REVISTA DE LA SEECI.

Ramírez Cuicas, Tulio; D[Aubeterre López, María Eugenia; Álvarez Rodríguez, Juan Carlos (2009): Construcción y validación de un inventario de percepción de estresores en docentes de educación básica. No 19. Julio. Año XII, . Páginas: 23- 5 , 661 [ण

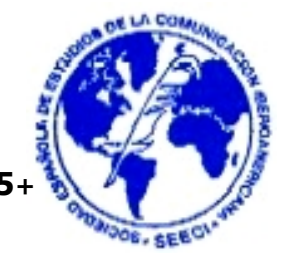

\title{
CONSTRUCCIÓN Y VALIDACIÓN DE UN INVENTARIO DE PERCEPCIÓN DE ESTRESORES EN DOCENTES DE EDUCACIÓN BÁSICA
}

\section{CONSTRUCTION AND VALIDATION OF AN INVENTORY OF ESTRESORES's PERCEPTION IN TEACHERS OF BASIC EDUCATION}

\author{
AUTORES \\ Tulio Ramírez Cuicas. \\ Universidad Central de Venezuela (Venezuela). \\ tuliorc1@gmail.com \\ María Eugenia D'Aubeterre López \\ Universidad Metropolitana. Caracas (Venezuela). \\ mdaubete@ucab.edu.ve

\section{Juan Carlos Álvarez Rodríguez.} \\ Universidad Católica Andrés Bello. Caracas (Venezuela). \\ juancalvarez1272@gmail.com
}

\section{RESUMEN}

Se presenta una experiencia de construcción y validación de un inventario para valorar la percepción de estresores de docentes de Educación Básica (IPE-D), a partir del desarrollo de 5 fases: 1) inventario de ítems a partir de la identificación de situaciones generadoras de estrés en los docentes, 2) construcción de dimensiones e indicadores, 3) validez y confiabilidad del instrumento, 4) determinación de los factores generadores de estrés y 5) diseño del inventario. EI IPE-D quedó conformado por 93 ítems distribuidos en 12 factores, con una confiabilidad de .983; y validez de constructo 
REVISTA DE LA SEECI.

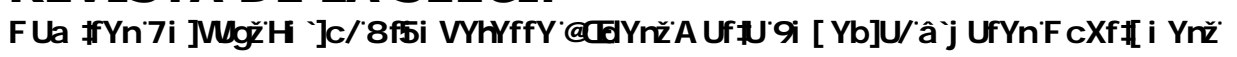

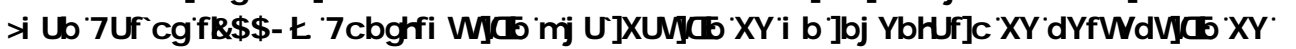

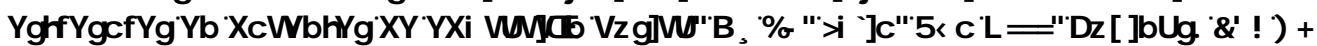

, 661

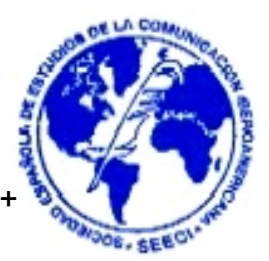

determinada por la consistencia entre la estructura teórica y la estructura empírica obtenida. El proceso de construcción se llevó a cabo a partir de respuestas dadas por 1788 docentes activos de Educación Básica de escuelas oficiales en 12 estados del territorio venezolano.

\title{
PALABRAS CLAVE
}

Percepción de estresares - Docentes - Confiabilidad - Validez - Análisis factorial

\begin{abstract}
It presents an experience of construction and validation of an inventory to assess the perception of stressors for basic education teachers (IPE-D), from the development of 5 phases namely consisted of five (5) phases: 1) identify the situations generating stress on teachers to develop an inventory of items, 2) dimensions and evaluation indicators of stressors, 3) validity and reliability of the instrument designed, 4) determining the factors of stress and 5) design and The inventory constitution IPE-D, was finally formed by 93 items distributed into 12 factors, with a .983 reliability and construct validity determined from the consistency between the theoretical structure and the structure established empirically obtained. The construction process was carried out from the answers given by 1788 assets of basic education teachers working in government schools in 12 states of Venezuela.
\end{abstract}

\section{KEY WORDS}

Perception of stressors - Teachers - Reliability - Validity - Factor analysis. 
REVISTA DE LA SEECI.

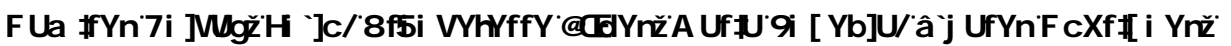

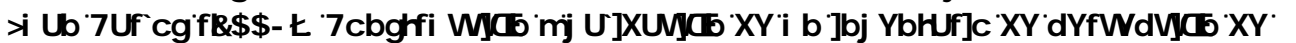

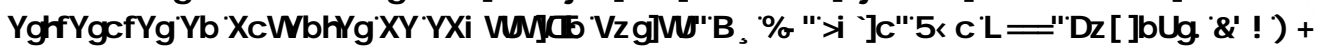

, 661

ÍNDICE

1. Introducción

2. Recolección de información para la elaboración de los indicadores

2.1. Muestra

2.2. Procedimiento y análisis

3. Fase II: Dimensiones e indicadores de evaluación de los estresores

3.1 Escala de valoración

4. Fase III: Validez y Confiabilidad del IPE-D

4.1 Indicadores de validez

4.2 Muestra de la prueba piloto

4.3 Indicadores de Confiabilidad

5. Fase IV. Determinación de los factores generadores de estrés.

5.1 Preparación

5.2 Factorización y rotación

5.3 Interpretación de los factores

6. Fase V. Diseño y constitución del inventario definitivo.

7. La medición en Ciencias Sociales. Algunas consideraciones finales

8. Bibliografía 
REVISTA DE LA SEECI.

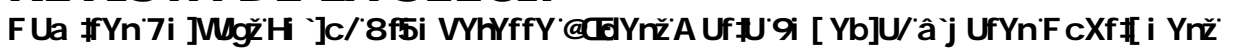

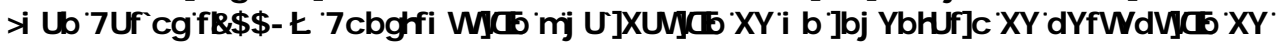

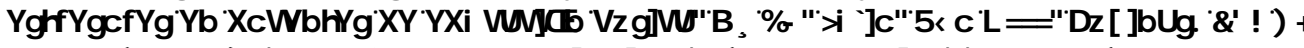

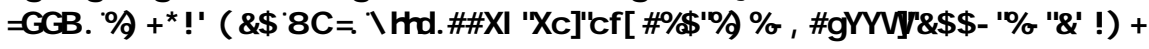

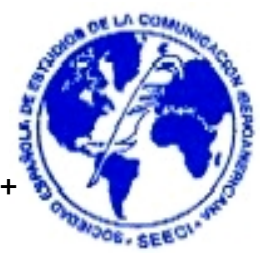

\section{Introducción}

La ambigüedad de los fenómenos relacionados con salud psicológica y su evaluación, traen como consecuencia que se minimice su importancia, sobre todo en alteraciones que cada vez parecen más comunes, de allí una escasa verificación objetiva de las fases iniciales de las enfermedades mentales que son evidentes en la mayoría de los casos cuando han llegado a etapas crónicas, y por ende poco reversibles, donde los signos y los síntomas ya son más evidentes. Actualmente se desarrollan múltiples alternativas como programas de mejora o de intervención para abarcar aquellos fenómenos que están relacionados con el bienestar psicológico de las personas, unos de impacto individual y otros de impacto colectivo que han mostrado tener menor o mayor éxito dependiendo de las características de la población a la cual está dirigida y del tiempo dispuesto para ello. Sin embargo, como plantea D'Aubeterre (2008) aun sigue en discusión los resultados de muchas de estas alternativas y la continuidad en el tiempo de sus efectos, por la poca sensibilidad de los diagnósticos iniciales y el contraste con los resultados finales, que puedan ofrecer indicadores empíricos de diagnóstico de y cambio. En el caso particular de la relación entre la salud psicológica del individuo y su entorno (de su influencia benigna o maligna), es imprensindible el estudio de las condiciones laborales y las formas como estas son percibidas, ya que es allí donde el individuo invierte la mayor cantidad de su tiempo productivo Tal preocupación ha surgido particularmente en espacios escolares o académicos en el cual el docente se convierte en el eje central de atención.

Ponce, Bulnes, Aliaga y Atalaya (2005) afirman que dadas las características y el contexto en el que se ejerce la docencia esta profesión presenta un mayor riesgo de ser estresante, razón por la cual se han dedicado diversas investigaciones al estudio de los factores que intervienen en este proceso en el campo de la enseñanza así como a 
REVISTA DE LA SEECI.

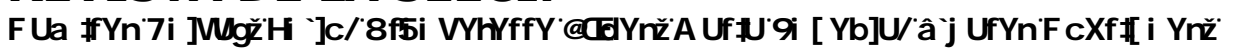

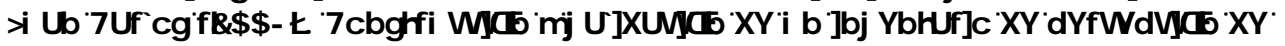

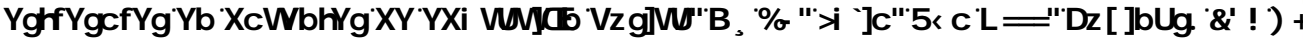

, 661

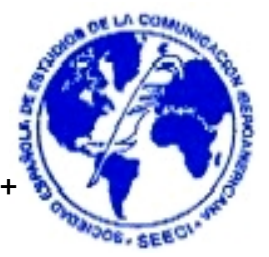

encontrar posibles vías de intervención; incluso se han propuesto algunas fuentes de estrés en docentes que son consideradas como las más sobresalientes: "actitudes negativas por parte de los alumnos, problemas de disciplina en el aula, malas condiciones de trabajo (número excesivo de alumnos en las aulas y falta de equipo adecuado, presiones temporales y sobrecarga de trabajo, conflictos entre los profesores, cambios rápidos en las demandas de currículo y organización" (pág. 92).

Definir el estrés desde la propuesta de Lazarus y Folkman (1986) y Lazarus (2000), implica "una relación particular entre el individuo y el entorno, que es evaluado por éste como amenazante o desbordante de sus recursos y que pone en peligro su bienestar" (pág. 43). De allí que, ante una situación estresante, la persona acciona mecanismos 0 estrategias de afrontamiento a fin de evitar, escapar o reducir la sensación de amenaza o controlar la situación. De acuerdo con esta teoría, el estrés puede tener un efecto perjudicial o beneficioso, dependiendo de la valoración subjetiva de tipo afectivocognitiva que el individuo haga de una situación particular; y como consecuencia cuando valore una situación como amenazante o de daño/pérdida, se producirían los efectos nocivos del estrés, pero cuando la misma situación se valore como desafiante, se producirían los efectos positivos del estrés.

Particularmente en esta relación se consideran tres elementos a destacar: el estimulo estresor, el proceso de evaluación y la respuesta o estrategia de afrontamiento. En general, los estresores se definen como todo evento, situación o cognición que puede evocar emociones positivas o negativas en el individuo (como activadores de conducta, emoción o cognición) y están implicados en la etiología de la salud psicológica y física, y de algunos resultados comportamentales relacionados con la salud. Al respecto una exposición intensa o prolongada a estos estresores puede causar graves problemas tanto físicos como psicológicos tal como lo destacan López, Osca y Peiró (2007). 
REVISTA DE LA SEECI.

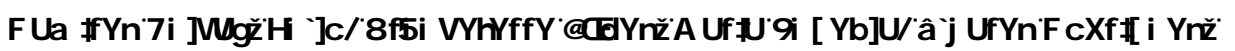

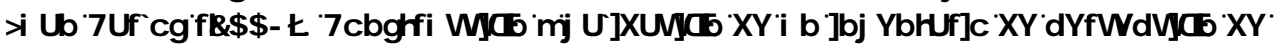

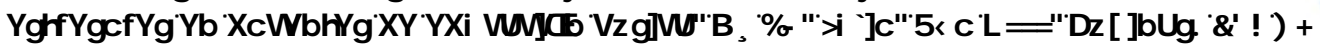

, 661

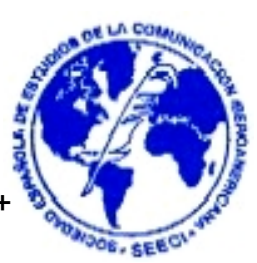

Si se adapta el concepto general de estrés al ámbito de trabajo, este se podría entender como el resultado del desajuste entre las demandas laborales y la capacidad de las personas de llevarlas a cabo. Desde esta perspectiva el estrés y el surgimiento de afecciones a la salud, se generan cuando las exigencias del trabajo no se ajustan a las necesidades, expectativas o capacidades del trabajador. El ajuste de expectativas dependerá de los factores situacionales como de las características individuales (Slipak, 1996, cit. por Riera, 2006). Sin embargo, el asumir esta perspectiva tan aislada (exigencias laborales vs capacidades del trabajador), de las condiciones del contexto y condiciones personales, puede llevarnos a un error de generalización, que no corresponde exactamente con el comportamiento del fenómeno. A esto debe sumarse la necesidad de identificar aquellas condiciones que son valorados colectivamente de forma similar (positiva o negativa), lo cual supondría un proceso de objetivación del fenómeno común, tal como lo plantea Berguer y Luckman (2001); solo a partir de allí será posible entonces desde una lógica inductiva, tipificarlos como estresores, y por ende generar propuestas de intervención de mayor alcance.

Cuando la intención es estudiar el estrés o identificar estímulos estresores, las alternativas de medición son innumerables y sus alcances pueden o no estar limitados en función del interés del investigador, por ejemplo, acciones o situaciones que el evaluado debe valorar; o un experto o varios que puntúan, o generar indicadores de situaciones y/o comportamientos. Cada una de las alternativas de aproximación al fenómeno (entrevistas, cuestionarios, evaluaciones conductuales, pruebas psicológicas 0 escalas e valoración), posee ventajas y desventajas que deben ser consideradas a la hora de su selección.

Si asumimos el hecho de que el estrés es producto de una experiencia psicológica; la manera de aproximarse al fenómeno es a partir de la valoración de eventos estresantes. La importancia de realizar estudios diagnósticos sobre estrés no es meramente 
REVISTA DE LA SEECI.

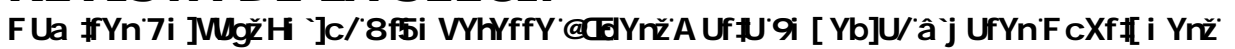

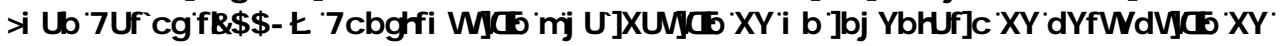

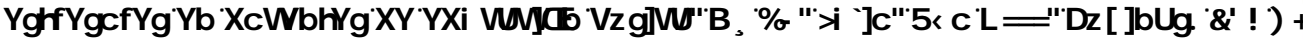

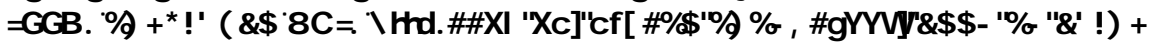

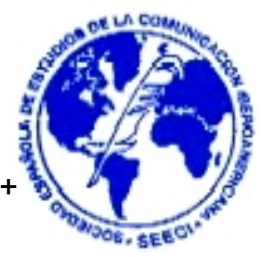

contemplativa sino preventiva ya que el impacto acumulativo de estos eventos estresante, tiene a mediano o largo plazo consecuencias en la salud (Taylor, 2003). En el caso que nos ocupa, la identificación de los factores estresantes que forman parte de un rol como el del docente, aumenta la posibilidad de rediseñar contextos laborales e implementar intervenciones para el manejo del estrés.

Es por ello, que el objetivo de este trabajo, es la construcción de un instrumento de valoración de eventos estresantes, que permita en el contexto de peritaje o de diagnóstico de salud ocupacional, la identificación de factores estresantes para el trabajador como una alternativa válida y confiable. Particularmente, en esta experiencia, se ofrece una alternativa de evaluación ajustada a un rol particular considerando condiciones propias de su labor y de su entorno; ofreciendo de esta manera una herramienta que permita una visión más específica de las fuentes generadores del estrés y por ende la generación de alternativas dirigidas a la mejora de las condiciones del trabajo y del bienestar psicológico.

El procedimiento llevado a cabo para la construcción del "Inventario de Percepción de Estresores en Docentes" (IPE-D), constó de cinco (5) fases: recolectar información y catalogar las situaciones generadoras de estrés en los docentes para la elaboración de un inventario de indicadores, dimensiones e indicadores de evaluación de los estresores, validez y confiabilidad del instrumento diseñado, determinación de los factores generadores de estrés y diseño y constitución del inventario definitivo. 


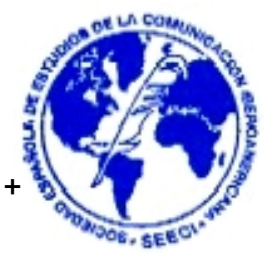

\section{Fase I: Recolección de información para la elaboración de los indicadores}

El inicio de esta fase implicó una revisión de antecedentes de evaluación en investigaciones sobre estrés con el fin de identificar alternativas a la aproximación del fenómeno en cuanto a su estructura, dimensiones e ítems. La línea de investigación centrada en la identificación de eventos estresantes parte de las propuestas de Holmes y Rahe (1967, cit. por Taylor, 2003), quienes desarrollaron un inventario de eventos estresantes, a los cuales se les asignaban valores numéricos. Este estudio demostró asociaciones significativas entre la presencia de estos eventos y la aparición de enfermedades. Esta aproximación puede ser válida, sin embargo, ha sido muy criticada por la generalidad de los eventos propuestos, los cuales pueden ser valorados de manera positiva o negativa, de acuerdo a como han sido vivenciados por las personas, de allí, la necesidad de diseñar inventarios más específicos a roles o áreas, que permitirán reducir estos niveles de generalidad tan poco útiles. Como parte de esta misma línea de investigación, algunas aproximaciones han apostado a la evaluación de los eventos cotidianos o incomodidades, que presentados diariamente, reducen el bienestar psicológico a corto plazo y producen síntomas físicos (Pelechano, Matud y De Miguel, 1994).

Interesados en esta postura, cuando intentamos evaluar los eventos generadores de estrés en un rol particular como el del docente, son muchas las variables que deben ser consideradas, ya que, parafraseando a Flores (2001), el profesorado es el responsable de que los alumnos aprendan, pero además de esto, las responsabilidades que originalmente estaban asignadas a los padres y a la comunidad han sido atribuidas a los docentes en cuanto a formación intelectual, en valores y respeto a las normas, entre otros. Aunado a esto, ha sido reiterado responsabilizar a los docentes de las fallas en el 
REVISTA DE LA SEECI.

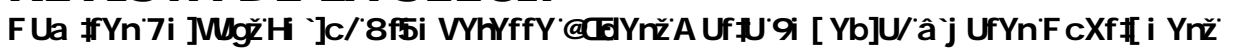

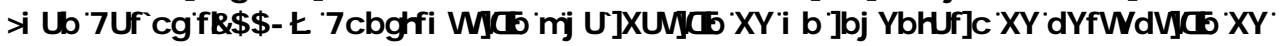

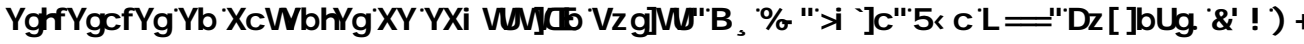

, 661

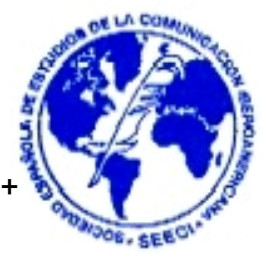

sistema educativo, lo cual, sumado a los bajos salarios y a condiciones de trabajo no siempre acordes con la delicada labor que cumplen, genera una tensión adicional. Sobre la base de estas premisas, identificar las condiciones generadores de estrés en docentes va mas allá de analizar las tareas diarias que realiza en su aula de clase. La naturaleza asistencial del trabajo docente, amerita la inclusión de otros elementos que no son considerados en la evaluación de un ambiente laboral tradicional. La naturaleza y características de la labor docente distan mucho del trabajo realizado en organizaciones donde el rendimiento, las responsabilidades y problemas laborales obedecen a una lógica totalmente diferente al trabajo magisterial. Así, ítems diseñados para recoger información sobre estrés en trabajadores de organizaciones empresariales de producción de bienes materiales con altos criterios de rentabilidad, no serían los más adecuados para medir esta misma variable en un contexto laboral cuya productividad es intangible a corto plazo y los cánones de rendimiento no pueden ser medibles directamente en términos de valor producido.

En esta misma lógica y con el propósito de conocer aquellos aspectos propios del trabajo docente que lo diferencian de otro tipo de labores, se diseñó una estrategia que permitiese conocer las tareas y situaciones específicas a los cuales se enfrenta el docente venezolano de Educación Básica en su labor diaria. Para esto se diseñó una entrevista abierta a profundidad siguiendo las recomendaciones de autores como Bingham y Moore (1973); Bodgan y Taylor (1996); Strauss y Corbin (2002); y Hernández, Fernández y Baptista (2006), Ramírez, D’Aubeterre y Álvarez (2008). La idea consistió en entrevistar a docentes de Educación Básica activos a la fecha que al dar respuesta a los planteamientos presentados, presentados en la Tabla 1, que permitiesen identificar los elementos o situaciones ligadas tanto al trabajo en sí mismo, la escuela, o al contexto extraescolar que, de acuerdo a la vivencia de cada entrevistado, le generaba mayor tensión, ansiedad o angustia. 


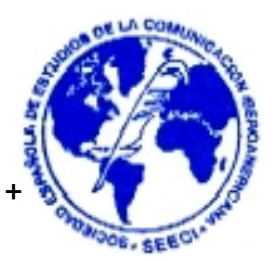

Tabla 1

Preguntas abiertas

1.- ¿Cuáles situaciones en el aula te generan tensión, ansiedad 0 angustia?

2.- ¿Cuáles situaciones en la escuela donde trabajas te generan tensión, ansiedad 0 angustia?

3.- ¿Cuáles situaciones fuera de la escuela te generan tensión, ansiedad o angustia?

\subsection{Muestra}

Estas entrevistas fueron realizadas a 84 docentes de aula que laboran en la Primera y Segunda Etapa de la Educación Básica en planteles oficiales y privados de 3 estados de Venezuela: Distrito Capital, Barquisimeto y Ciudad Bolívar. La participación de estos docentes fue de manera voluntaria, por lo que no se realizó ningún procedimiento de muestreo para su selección. Cada entrevista duró en promedio una (01) hora y treinta (30) minutos, completándose en total un promedio de 109 horas de entrevistas.

\subsection{Procedimiento y análisis}

A los planteamientos presentados, los docentes ofrecieron respuestas abiertas que de acuerdo a su extensión podrían ser replanteadas, que permitiesen generar un dialogo abierto, favoreciendo la identificación de la mayor cantidad de aspectos que le generaban estrés, tensión, angustia o ansiedad de su labor diaria. Estas respuestas fueron grabadas previa autorización del docente y transcritas, y posteriormente 
REVISTA DE LA SEECI.

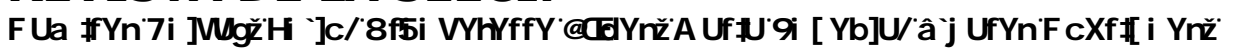

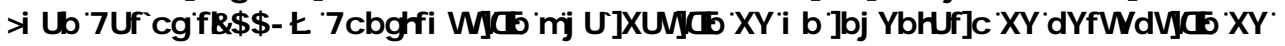

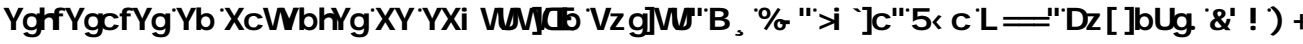

, 661

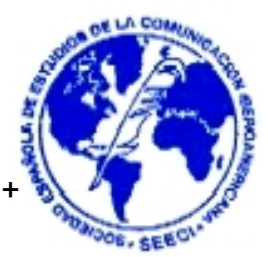

seccionadas por frases que permitiesen identificar aspectos de contenido, comunes y no comunes. Del análisis de contenido de cada frase se identificaron 601 situaciones que ocasionan o han ocasionado estrés a los entrevistados, basados en las respuestas más frecuentas a las preguntas abiertas de las entrevistas, que finalmente fueron agrupadas en 67 categorías, diferentes entre sí, como insumo de los indicadores del IPE-D, .

A estas categorías, se le sumaron 26 indicadores surgidos en un estudio previo realizado por Ramírez, D’Aubeterre y Álvarez (2008), los cuales aluden a las políticas del Estado referidas a la elaboración e implementación de un nuevo Diseño Curricular para la Educación Básica, a aspectos relacionados con condiciones de infraestructura de las instituciones educativas, al servicio que presta el Instituto de Previsión y Asistencia Social para el Personal del Ministerio de Educación (IPASME), la supervisión escolar, la politización de las relaciones laborales, la autonomía del docente en el aula de clases, la injerencia de la sociedad de padres y representantes en las actividades inherentes al personal docente, entre otras. Aún cuando estos indicadores no son producto de las respuestas de los docentes a las entrevistas abiertas (67 indicadores anteriores), fueron incorporados por ser de interés para el análisis de la labor docente en Venezuela, y por hacer referencia al contexto de la sociedad venezolana en general y en consecuencia a los docentes que la integran. Esta estrategia permitió seleccionar de una doble fuente los ítems de la primera versión del IPE-D, quedando un banco de 93 ítems. Esta estrategia proporcionó información sobre aspectos estresores muy específicos de la realidad docente venezolana, que no fueron tomados en cuenta por los instrumentos revisados. 


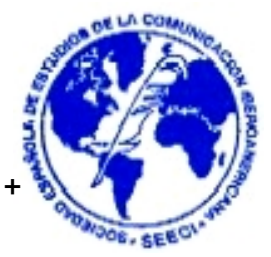

\section{Fase II: Dimensiones e indicadores de evaluación de los estresores}

Los 93 indicadores producto de la Fase I fueron analizados inductivamente con el fin de establecer el hilo conductor que los agrupa de manera teóricamente coherente. Ese ejercicio de agrupación permitió identificar las dimensiones que conforman la variable objeto de interés, a saber, Percepción de estresores. Los indicadores se agruparon en 10 dimensiones: Condiciones de la escuela, Condiciones de trabajo, Trabajo en sí mismo, Autoridades de la escuela, Alumnos, Colegas, Padres y representantes, Comunidad, Políticas del Estado y el Entorno social.

\subsection{Escala de valoración}

Tal como plantean Cohen y Swerdlik (2002), la medición de fenómenos psicológicos mediante cuestionarios implica no solo desarrollar ítems apropiados para la prueba, sino también maneras apropiadas para calificar e interpretar los resultados, que se derivan de las puntuaciones de la prueba como expresiones de las respuestas de las personas. Para la construcción del IPE-D fue considerado el método de escalamiento Lickert como alternativa de respuesta como valoración graduada a los indicadores presentados con puntajes que van del 1 al 5, considerando que mayores puntuaciones en la escala destacan aquellos indicadores que son percibidos, por el sujeto que responde, como generadores de estrés y viceversa. Es indispensable señalar que el número de categorías de respuesta debe ser igual para todas las afirmaciones, respetando el mismo orden de presentación de las opciones para todas las frases (Hernández y cols 2006). Ahora bien, se asume que la puntuación que un sujeto asigne a una afirmación, tomará en cuenta tanto la significación del enunciado como el punto de la escala que fue comprobado o cotejado, tal como lo plantean Thorndike y Hagen (1980). 
REVISTA DE LA SEECI.

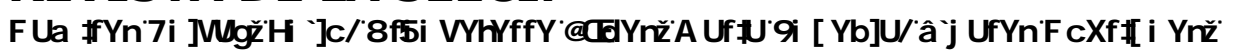

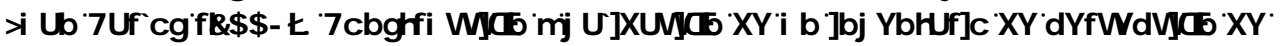

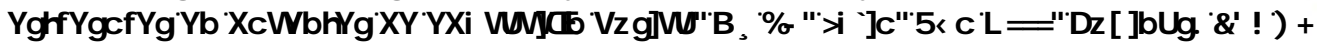

, 661 四

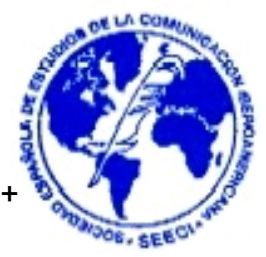

Las valoraciones consideradas para la escala fueron construidas en términos de frecuencia, de manera que el significado de cada una fue el siguiente: $1=$ No me genera estrés, $2=$ Me genera poco estrés, 3=Me genera moderado estrés, $4=$ Me genera bastante estrés y $5=$ Me genera mucho estrés. Esta escala mantiene una simetría entre sus extremos lo que posibilita una mejor manifestación de la variabilidad a lo largo de todos los ítems; por eso, la importancia de mantener el mismo orden o jerarquía de presentación en todas las afirmaciones de manera que se obtengan un mismo tipo de juicio en todos los casos.

El IPE-D ha sido diseñado para que las variables sean tratadas en un nivel de medida de intervalo, asumiendo que existe un continuo entre los rangos ( 1 a 5), y las distancias entre cada intervalo son iguales, tal como lo expresan Goode y Hatt (1975) y Ander-Egg (1982). Por su parte, Hernández y cols (2006), refieren que para este tipo de escalamientos, la obtención de los resultados totales para cada dimensión de las variables consideradas, se consiguen sumando los valores alcanzados respecto a cada frase dividido entre el número de afirmaciones o ítems. A fin de obtener puntajes globales de la escala se promedian los resultados de cada una de las dimensiones.

\section{Fase III: Validez y Confiabilidad del IPE-D}

De acuerdo con los criterios técnicos exigidos que se utilizan para calificar la calidad de cualquier instrumento de evaluación, es necesario garantizar lo que Cohen y Swerdlik (2002), denominan como solidez psicométrica, y que hace referencia a las características de validez y confiabilidad. 
REVISTA DE LA SEECI.

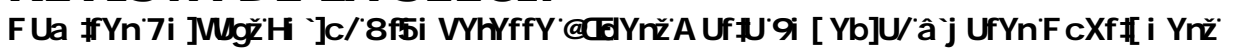

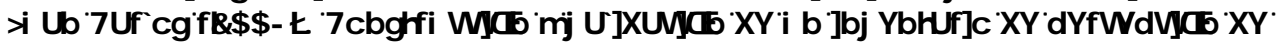

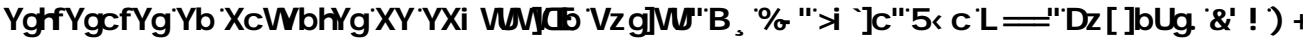

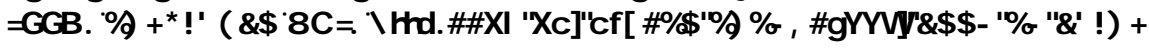

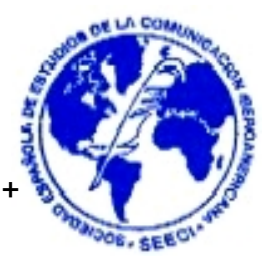

\subsection{Indicadores de validez}

La validez del instrumento puede ser determinado mediante múltiples procedimientos que ofrezcan una aproximación de que el instrumento mida lo que pretende medir (Ruiz, 2002). El IPE-D fue sometido a un procedimiento de validez de contenido, para ello se convocó a un grupo de 6 expertos (profesionales de la docencia con experiencia reconocida en investigación educativa), quienes valoraron la congruencia de cada uno de los ítems respecto de los propósitos del test (evaluación teórica). De esta primera revisión se reformularon o redactaron nuevamente un total de 27 ítems generándose una segunda versión del instrumento.

Esta nueva versión del instrumento fue revisada por otros 6 profesionales de la docencia convocados para tal fin ( 4 docentes que laboran en la lera y 2 da etapa de la Educación Básica, 1 ex Director de una Escuela Básica y 1 profesional de la psicología), quienes cotejaron los ítems con los objetivos de la investigación utilizando el Método del Coeficiente de Proporción por Rango. El resultado de este método es un coeficiente que permite la evaluación del instrumento construido, a partir de la asignación de una valoración en un rango determinado, en este caso del 1 al 4, en función de su correspondencia con las variables de las que se pretende deben recoger información, dando una valoración de: $1=$ Deficiente; $2=$ Regular; $3=$ Bueno y $4=$ Excelente. $\mathrm{El}$ Coeficiente de Proporción de Rangos como medida de acuerdo entre expertos (correlación) arrojó como resultado .77 indicando un alto nivel de correlación y por ende de validez entre expertos. Al evaluar los resultados obtenidos, se evidenció que 7 ítems de los 93, arrojaron puntuaciones promedios de .58, lo que indicaría que son ítems que deben ser evaluados, modificados o eliminados, sin embargo, por presentar alta frecuencia de respuestas entre los 84 entrevistados en la Fase I se tomó la decisión de no eliminarlos. Los ítems en discusión fueron: condiciones de los pupitres/ escritorios, 
REVISTA DE LA SEECI.

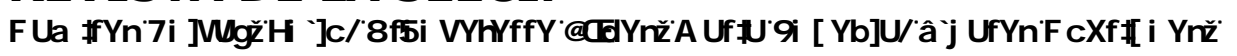

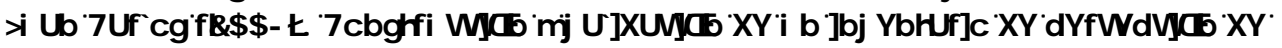

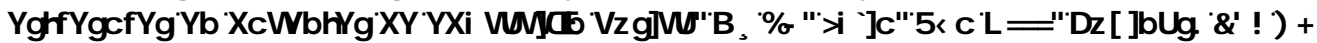

, 661

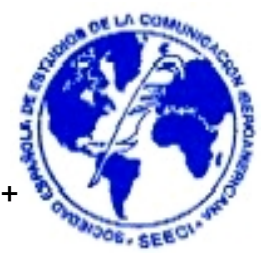

condiciones de las aulas de informática, carencia de especialistas (psicólogos y psicopedagogos), carencia de personal administrativo, carencia de suplentes y auxiliares, condiciones socioeconómicas e interés por el desarrollo académico de los estudiantes.

\subsection{Muestra de la prueba piloto}

Para llevar cabo esta etapa, se dispuso de una muestra de 1788 docentes de la Primera y Segunda Etapa de la Educación Básica en Venezuela (los primeros seis grados de formación de todo individuo en el país), distribuidos en 12 estados del territorio venezolano, activos para el periodo 2007-2008. El muestreo que se llevó a cabo fue no probabilístico de tipo accidental (Kerlinger y Lee, 2002), ya que las unidades de análisis se conformaron por los docentes que accedieron voluntariamente a participar en el estudio. Esta decisión se tomó debido a la dificultad de obtener muestras aleatorias a nivel nacional, lo que acarrea dificultades de generalización de los resultados descriptivos que puedan generarse de los datos obtenidos. La logística de recolección de información estuvo a cargo de los sindicatos magisteriales regionales afiliados a la Federación Venezolana de Maestros (FVM). Esta organización gremial colaboró en el proceso de distribución de los instrumentos de recolección de datos en los estados que participaron en el estudio, para ello fueron generadas instrucciones estándares de aplicación de los instrumentos para unificar los criterios y condiciones de aplicación.

\subsection{Indicadores de Confiabilidad}

La Confiabilidad, se define como la estabilidad de los resultados de una prueba, su determinación se basa en la medición de la consistencia de las respuestas de los sujetos con respecto a los ítems del instrumento. Esta medida se obtuvo aplicando el 
REVISTA DE LA SEECI.

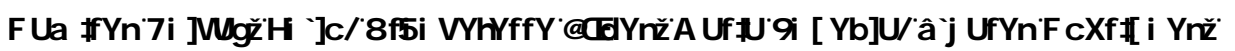

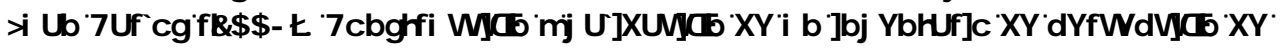

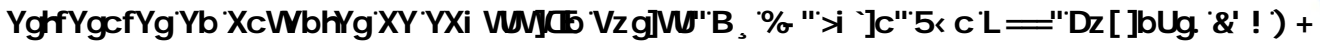

, 661 四

Coeficiente de Confiabilidad de Cronbach (también Ilamado Alpha de Cronbach), que requiere de una sola aplicación del instrumento y hace referencia a la consistencia interna. El resultado del coeficiente debe estar comprendido entre 0 y 1 , al igual que el Coeficiente de Proporción de Rangos utilizado en el proceso de validación. Mientras más se acerque este coeficiente a 1 más confiable es el instrumento; y se aprecia como medidas altas del coeficiente valores superiores a .8. En caso de que el coeficiente arroje valores por debajo del criterio asumido se recomienda revisar la redacción de los ítems, o excluirlos, en los casos en que el coeficiente se acerque a 0 . Este índice resultante para el análisis de la confiabilidad del instrumento es una medida de la estabilidad del contenido, más no de la consistencia en el tiempo, dada la naturaleza del fenómeno que se está estudiando, por lo cual no puede garantizarse el poder predictivo del instrumento.

Para obtener el resultado de la confiabilidad del IPE-D, se aplicó el instrumento en su versión final para la muestra antes descrita de docentes de Educación Básica de Primera y Segunda etapa, a la que se les calculó el Alpha de Cronbach obteniendo un valor de .96 , lo cual refleja una alta consistencia interna entre los ítems de la escala, indicando alta confiabilidad. Al evaluar los ítems que componen la escala se presentan puntajes promedios para los 93 ítems entre 1.92 y 3.88 en la escala de 1 a 5 considerada, de igual manera, los desvíos se encuentran entre 1.17 y 1.54 puntos, lo que hace referencia a la heterogeneidad de la muestra piloto utilizada para el análisis de los ítems $y$ del inventario en general.

Las correlaciones entre los 93 ítems presentaron asociaciones que van desde puntuaciones bajas (.177) a moderadas altas (.778), esto indica que existe relación entre los ítems y que correspondería a la medición de un mismo fenómeno compuesto de varios factores o dimensiones (Yela (1997). Las correlaciones entre los ítems y el test total se encuentran entre .5 y .7. Por otro lado el valor de Alpha de Cronbach al ser 
REVISTA DE LA SEECI.

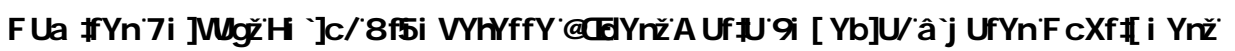

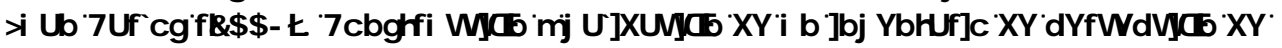

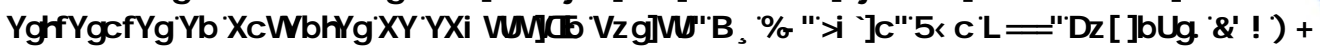

, 661

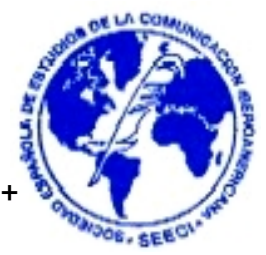

evaluado si cada uno de los ítems es eliminado no se ve significativamente. Haciendo referencia a las puntuaciones totales inventario, se presenta una media total de 3 puntos siguiendo la escala de 1 a 5 con un desvió de .84 puntos, indicando una variación de $29 \%$ de heterogeneidad en la muestra.

\section{Fase IV. Determinación de los factores generadores de estrés.}

Una vez construido el inventario y determinados sus indicadores de validez (de contenido) y confiabilidad (por consistencia interna), se procedió a la aplicación del instrumento en una muestra más heterogénea y de mayor tamaño para evaluar el comportamiento de las dimensiones construidas a partir de las Fases I y II, ya descritas. Sin embargo, para saber cómo estructurar tales dimensiones de manera empírica a partir de los datos, se efectúo un análisis factorial exploratorio. El análisis factorial (ANFAC) es una técnica estadística multivariante que sirve para determinar el número y la naturaleza de un grupo de constructos en un conjunto de mediciones (Hernández y cols 2006). En la psicología, el análisis factorial juega un papel preponderante en la identificación de rasgos psicológicos para analizar las interrelaciones de los datos conductuales. De acuerdo con Anastasi y Urbina (1998), "en el proceso de análisis factorial, se reduce el número de variables o categorías en cuyos términos puede describirse el desempeño de cada individuo a un número relativamente pequeño de factores o rasgos comunes" (pág.128). Un análisis factorial exploratorio se centra en encontrar el menor número de factores comunes que tengan en cuenta las correlaciones o covarianzas entre las variables. Tal como indica Yela (1997), a partir de esta técnica se pretenden identificar las dimensiones de variabilidad común existentes en el fenómeno de percepción de estrés, y cada una de estas dimensiones se les da el nombre de factor. Es importante señalar que para muchos autores este procedimiento de análisis multivariante se considera un método de evaluación de la validez de 
REVISTA DE LA SEECI.

Ramírez Cuicas, Tulio; D'Aubeterre López, María Eugenia; Álvarez Rodríguez, Juan Carlos (2009): Construcción y validación de un inventario de percepción de estresores en docentes de educación básica. No 19. Julio. Año XIII. Páginas: 23- 57 ISSN: 1576-3420 DOI: http://dx.doi.org/10.15198/seeci.2009.19.23-57

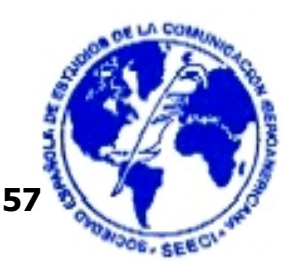

constructo del instrumento, ya que permite verificar la consistencia entre la estructura teórica propuesta y la estructura empírica subyacente; en efecto, para Hernández y cols (2006) "la evidencia de la validez del constructo se obtiene mediante el análisis de factores". Al respecto Magnusson (1969) considera que la validez del constructo se determina mostrando el grado de las consecuencias que pueden predecirse sobre la base de la teoría con respecto a los datos del test, lo cual puede ser evaluado a través de la correlación entre ítems aislados o diferentes partes del test, que deben tener una lata intercorrelación para considere una variable unitaria lo que se realiza a través de un análisis factorial. Tal método nos indica cuántas dimensiones integran a una variable y qué ítems conforman cada dimensión o factor. Para Hair, Anderson, Tatham y Black (2007),

"el propósito general de las técnicas analíticas de factores es encontrar una manera de condensar la información contenida en una serie de variables originales en una serie más pequeña de dimensiones compuestas o valores teóricos (factores) nuevos con una mínima pérdida de información" (pág. 83).

Para llevar a cabo este procedimiento se tomaron en cuenta las etapas que Yela (1997) sugiere, a saber, preparación, factorización, rotación e interpretación:

\subsection{Preparación}

Esta etapa plantea que una vez dispuesto el instrumento de evaluación, en este caso el IPE-D, se realiza una aplicación a una muestra lo suficientemente numerosa y variada para que puedan apreciarse las diferencias individuales. Para esta etapa de preparación se ha dispuesto de una muestra de 1788 docentes activos de educación básica de 
REVISTA DE LA SEECI.

Ramírez Cuicas, Tulio; D'Aubeterre López, María Eugenia; Álvarez Rodríguez, Juan Carlos (2009): Construcción y validación de un inventario de percepción de estresores en docentes de educación básica. No 19. Julio. Año XIII. Páginas: 23- 57 ISSN: 1576-3420 DOI: http://dx.doi.org/10.15198/seeci.2009.19.23-57

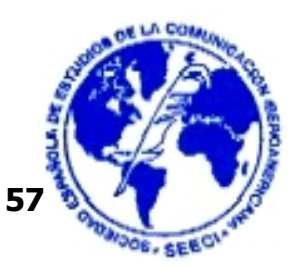

primera y segunda etapa, distribuidos en 12 estados del territorio venezolano activos para el periodo 2007-2008. Tal como se indicó con anterioridad el procedimiento de muestreo fue no probabilístico de tipo incidental. En la Tabla 2 presentada con anterioridad se indica la distribución de la muestra en los estados del territorio nacional.

\subsection{Factorización y rotación}

A fin de determinar la estructura factorial del instrumento, se procedió a realizar un análisis factorial de componentes principales (ACP) para extracción de factores con una solución fija a una rotación Varimax con Normalización de Kaiser y métodos de extracción por componentes principales. Este análisis se realizó con el fin de minimizar el número de variables que tienen saturaciones altas en cada factor simplificando así la interpretación de los factores. La idea implícita que se tiene con este método es que el primer factor explique el máximo de la varianza común que suministra las respuestas de los 1788 encuestados, el segundo factor el máximo de varianza restante e independiente del primer factor y así sucesivamente hasta obtener el último factor con un autovalor mayor a la unidad. Es importante señalar que debido a la no presencia de ítems que saturen en diferentes dimensiones podemos concluir que los factores, en efecto, son independientes entre sí. Los autovalores expresan la cantidad de varianza total que está explicada por cada dimensión, y los porcentajes de varianzas explicadas vinculados a cada dimensión se obtienen dividiendo su correspondiente autovalor por la suma de los autovalores. En síntesis, se seleccionaron aquellos factores con valores propios por encima de la unidad, que tuvieran más de tres ítems que explicaran la variabilidad del factor con valores por encima de .4 y factores que por su importancia teórica en la investigación no pudiesen ser eliminados. Para realizar el análisis factorial se utilizó el Programa Estadístico para las Ciencias Sociales SPSS/PC+ en su versión 17. 
REVISTA DE LA SEECI.

Ramírez Cuicas, Tulio; D'Aubeterre López, María Eugenia; Álvarez Rodríguez, Juan Carlos (2009): Construcción y validación de un inventario de percepción de estresores en docentes de educación básica. No 19. Julio. Año XIII. Páginas: 23- 57 ISSN: 1576-3420 DOI: http://dx.doi.org/10.15198/seeci.2009.19.23-57

La medida de adecuación muestral KMO (Kaiser-Meyer-Olkin) arrojó como resultado .967; valor alto que indica la pertinencia del uso del método de análisis factorial como técnica para establecer la validez del instrumento; la medida de adecuación muestral KMO contrasta si las correlaciones parciales entre las variables son suficientemente pequeñas. En cuanto a la prueba de esfericidad de Bartlett observamos que el nivel crítico es menor que .05 por lo tanto podremos rechazar la hipótesis nula de esfericidad y asegurar que el modelo factorial obtenido es adecuado para explicar los datos; la prueba de esfericidad de Bartlett contrasta la hipótesis nula de que la matriz de correlaciones es una matriz identidad, en cuyo caso no existirían correlaciones significativas entre las variables y el modelo no sería pertinente.

A continuación presentamos en la Tabla 2 la distribución de la Varianza Explicada por los Componentes Rotados de la estructura factorial de primer orden.

Tabla 2

Varianza total explicada por los componentes rotados. ANFAC de primer orden

\begin{tabular}{|c|c|c|c|c|c|c|c|c|c|}
\hline \multirow{2}{*}{ Factores } & \multicolumn{3}{|c|}{ Autovalores iniciales } & \multicolumn{3}{|c|}{$\begin{array}{l}\text { Suma de las saturaciones de la } \\
\text { extracción }\end{array}$} & \multicolumn{3}{|c|}{$\begin{array}{l}\text { Suma de las saturaciones a } \\
\text { cuadrado de la rotación }\end{array}$} \\
\hline & Total & $\mid \begin{array}{lr}\% & d \epsilon \\
\text { varianza }\end{array}$ & Acumulado & Total & $\mid \begin{array}{l}\% \quad \mathrm{~d} \\
\text { varianza }\end{array}$ & Acumulado & Total & $\left|\begin{array}{lr}\% & \text { de } \\
\text { varianza }\end{array}\right|$ & Acumulado \\
\hline 1 & 36.048 & 38.762 & 38.762 & 36.048 & 38.762 & 38.762 & 8.719 & 9.375 & 9.375 \\
\hline 2 & 6.685 & 7.188 & 45.949 & 6.685 & 7.188 & 45.949 & 8.209 & 8.827 & 18.203 \\
\hline 3 & 4.021 & 4.324 & 50.273 & 4.021 & 4.324 & 50.273 & 7.714 & 8.294 & 26.497 \\
\hline 4 & 3.530 & 3.796 & 54.069 & 3.530 & 3.796 & 54.069 & 5.646 & 6.070 & 32.567 \\
\hline 5 & 2.566 & 2.759 & 56.828 & 2.566 & 2.759 & 56.828 & 5.162 & 5.551 & 38.118 \\
\hline
\end{tabular}


REVISTA DE LA SEECI.

Ramírez Cuicas, Tulio; D'Aubeterre López, María Eugenia; Álvarez Rodríguez, Juan Carlos (2009): Construcción y validación de un inventario de percepción de estresores en docentes de educación básica. No 19. Julio. Año XIII. Páginas: 23- 57 ISSN: 1576-3420 DOI: http://dx.doi.org/10.15198/seeci.2009.19.23-57

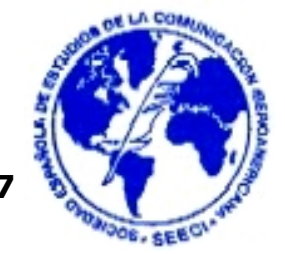

\begin{tabular}{l|l|l|l|l|l|l|l|l|l}
6 & 2.412 & 2.594 & 59.422 & 2.412 & 2.594 & 59.422 & 5.122 & 5.507 & 43.625 \\
7 & 2.112 & 2.271 & 61.693 & 2.112 & 2.271 & 61.693 & 5.028 & 5.406 & 49.031 \\
9 & 1.792 & 1.927 & 63.620 & 1.792 & 1.927 & 63.620 & 4.907 & 5.276 & 54.308 \\
10 & 1.561 & 1.678 & 65.298 & 1.561 & 1.678 & 65.298 & 3.882 & 4.174 & 58.482 \\
11 & 1.310 & 1.408 & 68.182 & 1.310 & 1.408 & 68.182 & 3.680 & 3.957 & 66.577 \\
12 & 1.168 & 1.256 & 69.438 & 1.168 & 1.256 & 69.438 & 2.024 & 2.176 & 68.752 \\
13 & 1.079 & 1.160 & 70.598 & 1.079 & 1.160 & 70.598 & 1.517 & 1.631 & 70.383 \\
14 & 1.062 & 1.142 & 71.740 & 1.062 & 1.142 & 71.740 & 1.261 & 1.356 & 71.740 \\
\end{tabular}

Método de extracción: Análisis de Componentes Principales.

Una vez agrupados los 93 ítems en los factores, se evalúa la comunalidad que representa la proporción de varianza con la que contribuye cada variable a la solución final, para evaluar si alcanza niveles aceptables de explicación. El valor criterio mínimo que utilizaremos siguiendo a Hair y cols (2001) es 0.5. A partir de los resultados ofrecidos en el análisis factorial las comunalidades para los 93 ítems oscilan entre 0.595 y 0.844, identificando así unos niveles aceptables de explicación.

\subsection{Interpretación de los factores}

A partir de los resultados ofrecidos, se identifican las cargas factoriales para cada variable (ítem) sobre cada factor (correlación variable factor), descritos en el Anexo 1, lo que permite interpretar la composición de cada uno de los factores resultantes. Tal como se indicó con anterioridad se consideran aquellas cargas factoriales alrededor de 
REVISTA DE LA SEECI.

Ramírez Cuicas, Tulio; D'Aubeterre López, María Eugenia; Álvarez Rodríguez, Juan Carlos (2009): Construcción y validación de un inventario de percepción de estresores en docentes de educación básica. No 19. Julio. Año XIII. Páginas: 23- 57 ISSN: 1576-3420 DOI: http://dx.doi.org/10.15198/seeci.2009.19.23-57

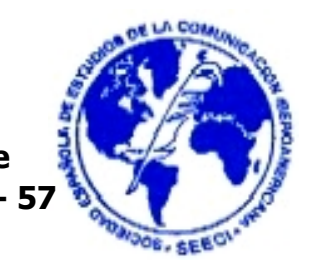

\pm 0.4 , de manera que "cuanto mayor sea el tamaño absoluto de la carga factorial, mas importante resulta la carga al interpretar la matriz factorial" (Hair y cols, 2001. p. 99). Luego de la identificación de las cargas significativas en cada uno de los 14 factores que surgieron del análisis factorial, se procede la interpretación de los factores con la asignación de un nombre o etiqueta, considerando el autovalor y el porcentaje de varianza explicada. A cada factor se incorpora también la redistribución de los ítems a partir de las dimensiones propuestas de manera teórica en la Fase II. Después de realizado el análisis de factores las doce dimensiones mantenidas en dicho análisis representan el $71,7 \%$ de la varianza total ya que estos factores presentan autovalores mayores a la unidad.

El primer factor extraído es igual a 36 y explica el 39\% de la varianza de los datos originales; este factor mide la percepción de estrés en docentes en cuanto a sus alumnos en el aula; en el saturan 11 ítems correspondientes al rendimiento académico, los hábitos de estudio, la evaluación del aprendizaje y desempeño, la asistencia a clases, el interés mostrado por las clases, la atención y memoria de los alumnos, el trabajo colaborativo por parte de los alumnos, los valores de los alumnos (honestidad, responsabilidad), el número de alumnos por aula, la puntualidad a clases, actividades programadas y el comportamiento en el aula. De los 17 ítems propuestos en la dimensión teórica 5, 11 ítems se mantienen conformando el factor 1

El segundo factor extraído es igual a 6.68 y explica el $7 \%$ de la varianza de los datos originales; con él se mide la percepción de estrés en docentes en cuanto al entorno; en dicho factor saturan 10 ítems correspondientes a: pobreza, violencia y agresividad, situación del país, situación económica del país, indigencia, tráfico automotor, desabastecimiento de alimentos, inseguridad personal, contaminación ambiental y 
REVISTA DE LA SEECI.

Ramírez Cuicas, Tulio; D'Aubeterre López, María Eugenia; Álvarez Rodríguez, Juan Carlos (2009): Construcción y validación de un inventario de percepción de estresores en docentes de educación básica. No 19. Julio. Año XIII. Páginas: 23- 57 ISSN: 1576-3420 DOI: http://dx.doi.org/10.15198/seeci.2009.19.23-57

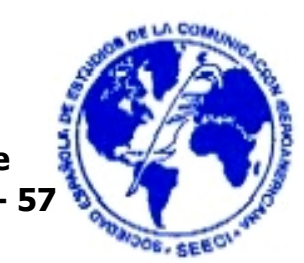

disponibilidad de la vivienda. De los 12 ítems propuestos en la dimensión teórica 10, cargan 10 ítems en la conformación del factor 2.

El tercer factor extraído es igual a 4 y explica el $4 \%$ de la varianza de los datos originales; este factor mide la percepción de estrés en los docentes en cuanto a las políticas del Estado, en este factor saturaron 10 ítems correspondientes a: contenidos del nuevo diseño curricular, implantación del nuevo diseño curricular, organización de talleres acerca del nuevo diseño curricular, discurso presidencial sobre la educación, estabilidad laboral, presencia efectiva de la zona educativa y el distrito escolar, políticas de ascenso para los docentes, interés del estado en solucionar las necesidades educativas, actuación de los gremios y sindicatos docentes y servicio del IPASME. De los 10 ítems propuestos en la dimensión teórica 9, cargan todos en la conformación del factor 3.

El cuarto factor extraído es igual a 3.53 y explica el $4 \%$ de la varianza de los datos originales; este factor mide la percepción de estrés en los docentes en cuanto a su trabajo como docente. Sólo saturaron 7 ítems en el factor: conocimiento de la temática a impartir, estrategias de enseñanza desarrolladas en clase, habilidades de dominio / manejo de grupo, autonomía en el aula, actualización profesional, tiempo para el trabajo en el aula y actualización de las tecnologías de la información y comunicación. De los 10 ítems de la dimensión teórica 3, cargan 7 ítems en la conformación del factor 4.

El quinto factor extraído es igual a 2.56 y explica el $3 \%$ de la varianza de los datos originales; este factor mide la percepción de estrés en los docentes en cuanto a los padres y representantes, en él saturaron 8 ítems correspondientes a: participación de las actividades programadas por la escuela, interés por las actividades de la escuela, 
REVISTA DE LA SEECI.

Ramírez Cuicas, Tulio; D'Aubeterre López, María Eugenia; Álvarez Rodríguez, Juan Carlos (2009): Construcción y validación de un inventario de percepción de estresores en docentes de educación básica. No 19. Julio. Año XIII. Páginas: 23- 57 ISSN: 1576-3420 DOI: http://dx.doi.org/10.15198/seeci.2009.19.23-57

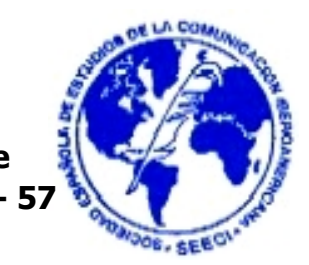

asistencia a las reuniones, dedicación de la formación de valores en sus hijos, valoración del trabajo del maestro, interés por el rendimiento académico de sus representados, confrontación con los representantes e intromisión en las actividades del docente. De los 8 ítems propuestos en la dimensión teórica 7, cargan todos en la conformación del factor 5 .

El sexto factor extraído es igual a 2.41 y explica el $3 \%$ de la varianza de los datos originales; este factor mide la percepción de estrés en los docentes en cuanto a las condiciones de la escuela, en él saturan 8 ítems correspondientes a: carencia de personal administrativo, condiciones de las aulas de informática, carencia de especialistas (psicólogos, psicopedagogos), carencia de personal obrero, carencia de suplentes y auxiliares, condiciones de los pupitres / escritorios, espacios destinados a la recreación de los alumnos y carencia de recursos didácticos. De los 12 ítems propuestos en la dimensión teórica 1, solo 7 ítems cargan en el factor 6, y un ítem extraído de la dimensión 2, conformándose así un factor de 8 ítems.

El séptimo factor extraído es igual a 2.11 y explica el $2 \%$ de la varianza de los datos originales; este factor refiere a la percepción de estrés en los docentes en cuanto a las autoridades de la escuela, en él saturan 8 ítems: comunicación de las decisiones a los docentes, relaciones con las autoridades de la escuela, interés por las necesidades de los docentes, evaluación de desempeño a los docentes, interés por el mantenimiento de la escuela, presencia y participación en las actividades de la escuela, relaciones con los docentes y directivos y mediación ante el Ministerio de para satisfacer necesidades docentes. De los 7 ítems propuestos en la dimensión teórica 4, cargan todos y un ítem de la dimensión 5, conformando 8 ítems el factor 7. 
REVISTA DE LA SEECI.

Ramírez Cuicas, Tulio; D'Aubeterre López, María Eugenia; Álvarez Rodríguez, Juan Carlos (2009): Construcción y validación de un inventario de percepción de estresores en docentes de educación básica. No 19. Julio. Año XIII. Páginas: 23- 57 ISSN: 1576-3420 DOI: http://dx.doi.org/10.15198/seeci.2009.19.23-57

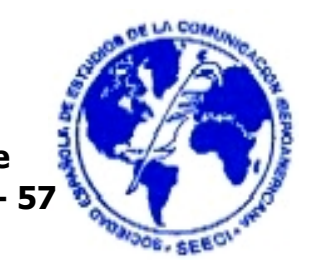

El octavo factor extraído es igual a 1.8 y explica el $2 \%$ de la varianza de los datos originales; este factor mide la percepción de estrés en los docentes en cuanto a sus colegas, en él, 7 ítems que explican su variabilidad son: cumplimiento de los compromisos laborales, interés por el trabajo, interés por el desarrollo académico, relaciones personales entre profesores, participación en las luchas por las reivindicaciones laborales, comunicación entre los colegas y el desempeño de los especialistas. De los 7 ítems propuestos en la dimensión teórica 6, cargan todos en la conformación del factor 8.

El noveno factor extraído es igual a 1.56 y explica el $2 \%$ de la varianza de los datos originales; este factor mide la percepción de estrés en los docentes en cuanto a la comunidad que rodea a su escuela y en él saturan 5 ítems correspondientes a: atención mostrada por las condiciones de la institución, participación en las labores de mantenimiento de la escuela, actitud mostrada ante las iniciativas de la escuela, injerencia de la contraloría social en las actividades de la escuela, déficit de cupos disponibles para la comunidad. De los 5 ítems propuestos en la dimensión teórica 8 , cargan todos en la conformación del factor 9.

El décimo factor extraído es igual a 1.37 y explica el $1 \%$ de la varianza de los datos originales; este factor mide la percepción de estrés en los docentes en cuanto a las condiciones laborales. Los 7 ítems que explican este factor son: tiempo para el trabajo administrativo (boletas, y registros), tiempo para planificar y tiempo para dedicado a los talleres del nuevo diseño curricular. Otros ítems que explican la variabilidad del factor son: beneficios salariales, supervisión escolar por parte de la Zona Educativa, trabajo de doble turno, y politización de las relaciones laborales. De los 5 ítems propuestos en la dimensión teórica 2, solo 4 ítems cargan en el factor 10, y 3 ítems extraídos de la dimensión 3, conformándose así un factor de 7 ítems. 
REVISTA DE LA SEECI.

Ramírez Cuicas, Tulio; D'Aubeterre López, María Eugenia; Álvarez Rodríguez, Juan Carlos (2009): Construcción y validación de un inventario de percepción de estresores en docentes de educación básica. No 19. Julio. Año XIII. Páginas: 23- 57 ISSN: 1576-3420 DOI: http://dx.doi.org/10.15198/seeci.2009.19.23-57

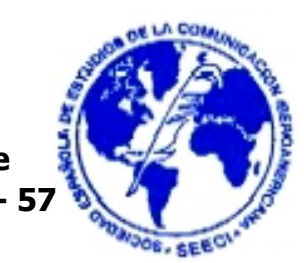

El decimoprimero factor extraído es igual a 1.31 y explica el $1 \%$ de la varianza de los datos originales; consideramos adecuado llamar este factor percepción de estrés en los docentes en cuanto a la infraestructura física de la institución que está saturado por 5 ítems: condiciones de ventilación, condiciones de iluminación, condiciones de limpieza, ruido en la institución / aula, espacio para el trabajo en las aulas. De los 12 ítems propuestos en la dimensión teórica 1, solo 5 ítems cargan en el factor 11.

El decimosegundo factor que cumple con las condiciones mínimas para pertenecer a la estructura factorial, es igual a 1.16 y explica el $1 \%$ de la varianza de los datos originales; este factor mide la percepción de estrés en los docentes en cuanto a las condiciones personales de los alumnos, que está saturado por 4 ítems: condiciones de alimentación, condiciones de higiene, condiciones familiares y condiciones socioeconómicas. De los 17 ítems propuestos en la dimensión teórica 5, solo 4 ítems cargan en el factor 12 .

En lo que concierne a los factores 13 y 14 es importante destacar que, para pertenecer a la estructura factorial deben cumplir antes con ciertas condiciones, que en este caso, no son satisfechas; en efecto, en lo que respecta a exigir la presencia de más de 3 ítems en la conformación del factor, observamos que en el factor 13 sólo saturan dos ítems correspondientes a: traslado a la escuela y acceso a la escuela. Pero esto no debe preocuparnos, ya que la teoría nos permite considerar el segundo mejor comportamiento de saturación con valores mayores a .4 de la estructura factorial, que para los dos ítems antes mencionados corresponden al segundo factor concerniente a medir "en cuanto al entorno"; y considerando además que estos guardan relación con el resto de ítems del factor 2 , el problema se resuelve entonces eliminando el factor y reacomodando el ítem en el segundo factor de saturación con valor superior a \pm .4 . De forma análoga, un solo ítem satura en el factor 14 correspondiente a accidentes en el 
REVISTA DE LA SEECI.

Ramírez Cuicas, Tulio; D'Aubeterre López, María Eugenia; Álvarez Rodríguez, Juan Carlos (2009): Construcción y validación de un inventario de percepción de estresores en docentes de educación básica. № 19. Julio. Año XIII. Páginas: 23- 57 ISSN: 1576-3420 DOI: http://dx.doi.org/10.15198/seeci.2009.19.23-57

aula, pero al estudiar su segundo mejor comportamiento de saturación observamos que en el factor 1 su valor es de .474 por lo que podemos incorporarlo como ítem para medir la percepción de estrés en los docentes en cuanto a sus alumnos, correspondiente al factor 1 .

Ahora bien, los resultados del análisis factorial de primer orden discutido anteriormente nos exige eliminar los factores 13 y 14, al realizar un segundo análisis factorial con 12 factores preestablecidos en el SPSS (ANFAC de segundo orden), se corrobora to expresado antes respecto al reacomodo de los ítems que saturan en el factor 13 y 14, y se observa que en efecto la nueva estructura factorial incorpora los ítems en los factores 1 (12 ítems) y 2 (13 ítems), variando de manera muy poco perceptible los valores arrojados del análisis factorial de primer orden, tal como se presenta en la Tabla 3 en comparación con la Tabla 2. 
REVISTA DE LA SEECI.

Ramírez Cuicas, Tulio; D'Aubeterre López, María Eugenia; Álvarez Rodríguez, Juan Carlos (2009): Construcción y validación de un inventario de percepción de estresores en docentes de educación básica. № 19. Julio. Año XIII. Páginas: 23- 57 ISSN: 1576-3420 DOI: http://dx.doi.org/10.15198/seeci.2009.19.23-57

Tabla 3

Varianza total explicada por los componentes rotados. ANFAC de segundo orden

\begin{tabular}{|c|c|c|c|c|c|c|c|c|c|}
\hline \multirow{2}{*}{$\begin{array}{l}\text { Factore } \\
\mathrm{s}\end{array}$} & \multicolumn{3}{|c|}{ Autovalores iniciales } & \multicolumn{3}{|c|}{$\begin{array}{l}\text { Sumas de las saturaciones al } \\
\text { cuadrado de la extracción }\end{array}$} & \multicolumn{3}{|c|}{$\begin{array}{l}\text { Suma de las saturaciones al } \\
\text { cuadrado de la rotación }\end{array}$} \\
\hline & Total & $\begin{array}{l}\% \text { de la } \\
\text { varianza }\end{array}$ & $\begin{array}{l}\text { \% } \\
\text { acumulado }\end{array}$ & Total & $\begin{array}{l}\% \text { de la } \\
\text { varianza }\end{array}$ & $\begin{array}{l}\% \\
\text { acumulado }\end{array}$ & Total & $\begin{array}{l}\% \text { de la } \\
\text { varianza }\end{array}$ & $\begin{array}{l}\text { \% } \\
\text { acumulado }\end{array}$ \\
\hline 1 & 36.048 & 38.762 & 38.762 & 36.048 & 38.762 & 38.762 & 9.442 & 10.152 & 10.152 \\
\hline 2 & 6.685 & 7.188 & 45.949 & 6.685 & 7.188 & 45.949 & 8.296 & 8.921 & 19.073 \\
\hline 3 & 4.021 & 4.324 & 50.273 & 4.021 & 4.324 & 50.273 & 7.838 & 8.428 & 27.501 \\
\hline 4 & 3.530 & 3.796 & 54.069 & 3.530 & 3.796 & 54.069 & 5.510 & 5.924 & 33.425 \\
\hline 5 & 2.566 & 2.759 & 56.828 & 2.566 & 2.759 & 56.828 & 5.494 & 5.907 & 39.332 \\
\hline 6 & 2.412 & 2.594 & 59.422 & 2.412 & 2.594 & 59.422 & 5.167 & 5.556 & 44.888 \\
\hline 7 & 2.112 & 2.271 & 61.693 & 2.112 & 2.271 & 61.693 & 5.040 & 5.420 & 50.308 \\
\hline 8 & 1.792 & 1.927 & 63.620 & 1.792 & 1.927 & 63.620 & 4.779 & 5.138 & 55.446 \\
\hline 9 & 1.561 & 1.678 & 65.298 & 1.561 & 1.678 & 65.298 & 4.151 & 4.464 & 59.910 \\
\hline 10 & 1.373 & 1.476 & 66.774 & 1.373 & 1.476 & 66.774 & 3.870 & 4.161 & 64.071 \\
\hline 11 & 1.310 & 1.408 & 68.182 & 1.310 & 1.408 & 68.182 & 3.440 & 3.699 & 67.771 \\
\hline 12 & 1.168 & 1.256 & 69.438 & 1.168 & 1.256 & 69.438 & 1.551 & 1.667 & 69.438 \\
\hline
\end{tabular}

Método de extracción: Análisis de Componentes principales.

De hecho, tanto las medidas de adecuación muestral KMO (Kaiser-Meyer-Olkin) y esfericidad de Bartlett, así como la varianza total explicada por los componentes rotados de la estructura factorial para los doce factores; no presentaron variación alguna con respecto al análisis factorial de segundo orden. En lo que respecta a las saturaciones de los ítems al factor las variaciones rondan en las milésimas de valor. 
REVISTA DE LA SEECI.

Ramírez Cuicas, Tulio; D'Aubeterre López, María Eugenia; Álvarez Rodríguez, Juan Carlos (2009): Construcción y validación de un inventario de percepción de estresores en docentes de educación básica. No 19. Julio. Año XIII. Páginas: 23- 57 ISSN: 1576-3420 DOI: http://dx.doi.org/10.15198/seeci.2009.19.23-57

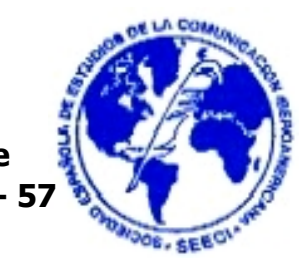

Al inicio de esta Fase IV, se hizo referencia al uso del análisis factorial como método de evaluación de la validez de constructo, al verificar la estructura teórica propuesta y su consistencia con la estructura empírica obtenida. Sobre la base de esta información recordamos que el instrumento partió de una estructura teórica de 10 dimensiones tal como se describen en la Fase II, y que los 93 ítems que constituían esta estructura teórica fueron evaluados a través de un procedimiento de análisis factorial exploratorio, con el cual se obtuvieron 12 dimensiones, que evidencian concordancia con las propuestas inicialmente, y en algunos casos reacomodaciones de ítems que mantienen la coherencia de contenido de las dimensiones propuestas. Finalmente, una vez obtenidos los factores empíricos a partir de las respuestas de los 1788 docentes que conformaron la muestra, se determinan nuevamente los indicadores de confiabilidad, tanto para del IPE-D con los 93 ítems como para los 12 factores, obteniéndose altos índices de consistencia interna.

Se puede observar que los valores Alpha obtenidos evidencian altos niveles de confiabilidad, lo que corrobora la apreciación obtenida a partir del análisis de confiabilidad realizado en la Fase III.

\section{Fase V. Diseño y constitución del inventario definitivo.}

En conclusión, y a partir de todo lo discutido con anterioridad, el IPE-D (ver Anexo 2) constituye un Inventario de Percepción de Estresores en Docentes, autoadministrado, compuesto por 93 ítems distribuidos en 12 factores que hacen referencia a la percepción de los docentes con respecto a: sus alumnos en el aula; el entorno; las políticas del Estado; el trabajo como docente; los colegas; los padres y representantes; las condiciones de la escuela; las autoridades de la escuela; la comunidad que rodea a su escuela; las condiciones laborales: la infraestructura física de la institución; y, las condiciones personales de los alumnos. La evaluación de los ítems es realizada a través 
REVISTA DE LA SEECI.

Ramírez Cuicas, Tulio; D'Aubeterre López, María Eugenia; Álvarez Rodríguez, Juan Carlos (2009): Construcción y validación de un inventario de percepción de estresores en docentes de educación básica. No 19. Julio. Año XIII. Páginas: 23- 57 ISSN: 1576-3420 DOI: http://dx.doi.org/10.15198/seeci.2009.19.23-57

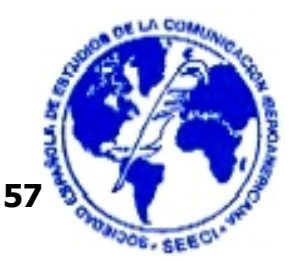

de una escala de valoración tipo Lickert donde $1=$ No me genera estrés, $2=$ Me genera poco estrés, $3=$ Me genera moderado estrés, $4=$ Me genera bastante estrés y $5=$ Me genera mucho estrés. Este inventario posee indicadores de consistencia interna de .96 calculados a través del Alpha de Cronbach, y fue validado a través de expertos a través del coeficiente de proporción por rangos de .77 indicando un alto porcentaje de acuerdo entre expertos. El análisis factorial exploratorio indica una alta consistencia entre la estructura teórica establecida y la estructura empírica presentada, garantizando la validez de constructo del IPE-D. Para obtener las puntuaciones en el IPE-D, deben realizarse rangos promediados, es decir, con las puntuaciones obtenidas por la valoración de los docentes que responden para cada dimensión, se suman y se promedian dichas puntuaciones entre el número de ítems que conforman dicha dimensión, esto permitirá obtener un valor en la escala del 1 al 5 que se estableció para valorar los ítems. Un puntaje global de percepción del estresor se obtiene promediando los puntajes por dimensión, siendo cada una de estas los estresores globales del ámbito laboral de los docentes de Educación Básica...

Es necesario destacar que este inventario ha sido diseñado para docentes de Educación Básica en Venezuela, por lo que cualquier aplicación que se realice del mismo en otras muestras de docentes, debe constar de las adaptaciones necesarias y la determinación de indicadores de validez y confiabilidad.

\section{La medición en Ciencias Sociales. Algunas consideraciones finales}

En esta experiencia se describen los aspectos metodológicos y teóricos que justifican el desarrollo de un instrumento de medición, capaz de valorar socialmente un constructo que hemos denominado factores generadores de estrés o estresores, cuya naturaleza 
REVISTA DE LA SEECI.

Ramírez Cuicas, Tulio; D'Aubeterre López, María Eugenia; Álvarez Rodríguez, Juan Carlos (2009): Construcción y validación de un inventario de percepción de estresores en docentes de educación básica. No 19. Julio. Año XIII. Páginas: 23- 57 ISSN: 1576-3420 DOI: http://dx.doi.org/10.15198/seeci.2009.19.23-57

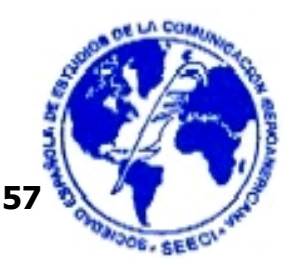

inicial es individual y subjetiva; pero que, para poder ser útil en el diagnóstico del fenómeno de estrés (psicólogo de la salud) y factible de ser gestionado a partir de políticas de recursos humanos (psicólogo de la salud psicológica ocupacional) y de políticas de auditoría interna (papel de peritaje del psicólogo jurídico), requiere tener una aproximación más objetiva, basada en el conjunto de las respuestas de los encuestados, que permita su consideración como un factor etiológico del estrés.

El establecimiento de tipologías estándar a partir de los estresores identificados y dado el análisis del origen de su presencia, permitirá establecer las responsabilidades y alternativas de intervención, según sea la fuente o el origen de los referidos estresores. Tal cualidad objetivada de una misma fuente etiológica de estrés por parte de una mayoría de miembros que compone un mismo sector ocupacional (maestros de escuelas oficiales de básica), hace que por el lado teórico, exista una mayor comprensión de la vivencia del estrés de un mismo sector laboral, e identifica si su impacto proviene de las características propias del rol laboral, de la vida cotidiana o de las interacciones de las características del rol con la vivencia personal. Finalmente, dado los criterios válidos ecológicamente de la medida (construcción del modelo factorial de forma inductiva), de consistencia interna y validez estructural, favorecen el desarrollo en posteriores investigaciones, de una sola medida general de estrés, que podría ser validada con su manifestación en otras variables de salud psicológica como bienestar subjetivo, calidad de vida, ansiedad y depresión; pero también otras asociadas como absentismo laboral, implicación laboral etc., lo cual favorecerá la estimación de elementos de protección y de riesgo a la salud psicológica en el trabajo realizado por maestros venezolanos pertenecientes a las dos primeras etapas de la Escuela Básica.

Finalmente creemos pertinente hacer mención de algunos aspectos que deben considerarse al momento de construir instrumentos de medición en una investigación 
REVISTA DE LA SEECI.

Ramírez Cuicas, Tulio; D'Aubeterre López, María Eugenia; Álvarez Rodríguez, Juan Carlos (2009): Construcción y validación de un inventario de percepción de estresores en docentes de educación básica. No 19. Julio. Año XIII. Páginas: 23- 57 ISSN: 1576-3420 DOI: http://dx.doi.org/10.15198/seeci.2009.19.23-57

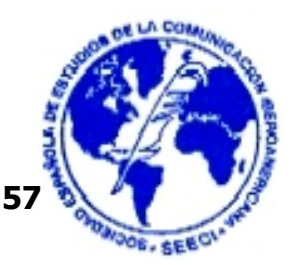

que pretenda abordar de manera sistemática un fenómeno social. Esos aspectos están vinculados a la determinación de lo que se quiere medir, la generación del conjunto de ítems, las escalas medición, determinación de indicadores de validez y confiabilidad, administración de los ítems a una muestra o población objeto de estudio, evaluación de los ítems y optimización de la escala de medición. Así mismo es de suma importancia destacar que el uso o adaptación que se le dé a un instrumento ya diseñado debe tomar en consideración tanto la población para la que se diseñó, como la población en la cual se pretende replicar la investigación. Este análisis previo dará las orientaciones necesarias para realizar adaptaciones pertinentes del instrumento para administrarse a otras muestras, en otros contextos.

Se destaca de aquí que los resultados de los estudios en las ciencias sociales deben ser producto de un trabajo serio, disciplinado, sistemático y riguroso, ya que es la manera de contribuir de manera efectiva con la prescripción de estrategias y soluciones que permitan solventar muchas de las situaciones anómalas que afectan a la sociedad de hoy. Un buen diagnostico siempre será el mejor punto de partida para solucionar un problema, cualquiera que este sea.

\section{Bibliografía}

ANASTASI, A. y URBINA, S. (1998). Test Psicológicos. Prentice-Hall Hispanoamericana. México D.F.

ANDER-EGG, E. (1982). Técnicas de investigación social. Humanitas. Buenos Aires, Argentina. 
REVISTA DE LA SEECI.

Ramírez Cuicas, Tulio; D'Aubeterre López, María Eugenia; Álvarez Rodríguez, Juan Carlos (2009): Construcción y validación de un inventario de percepción de estresores en docentes de educación básica. No 19. Julio. Año XIII. Páginas: 23- 57 ISSN: 1576-3420 DOI: http://dx.doi.org/10.15198/seeci.2009.19.23-57

BERGER, P., LUCKMANN, T. (2001). La construcción Social de la Realidad. Amorrortu Editores. Buenos Aires, Argentina.

BINGHAM, W y MOORE, B. (1973). Como entrevistar. Rialp. Madrid BODGAN, R. y TAYLOR, S. (1996). Introducción a los métodos cualitativos de investigación. Paidós. Barcelona.

COHEN, R.; y SWERDLIK, C. (2002). Pruebas y evaluación psicológicas. McGraw Hill Interamericana. México.

D'AUBETERRE, M. (2008). Factores que inciden en la percepción de estrés en docentes de Educación Básica en Venezuela. Tesis de especialización no publicada, Universidad Central de Venezuela, Caracas.

FLORES, M. (2001). El factor humano en la docencia de Educación Secundaria: un estudio de la Eficacia docente y el estrés a lo largo de la profesional. Tesis doctoral. Universitat Autónoma de Barcelona. España.

GOODE, W.; y HATT, P. (1975). Métodos de Investigación Social. Trillas. México.

HAIR, F.; ANDERSON, M.; TATHAM, P. y BLACK, J. (2007). Análisis multivariante. Prentice Hall. Madrid.

HERNÁNDEZ, R., FERNÁNDEZ, C. y BAPTISTA, P. (2006). Metodología de la Investigación. McGraw Hill Interamericana. México D.F. 
REVISTA DE LA SEECI.

Ramírez Cuicas, Tulio; D'Aubeterre López, María Eugenia; Álvarez Rodríguez, Juan Carlos (2009): Construcción y validación de un inventario de percepción de estresores en docentes de educación básica. No 19. Julio. Año XIII. Páginas: 23- 57 ISSN: 1576-3420 DOI: http://dx.doi.org/10.15198/seeci.2009.19.23-57

KERLINGER, F. y LEE, H. (2002). Investigación del comportamiento. McGraw-Hill Interamericana. México D.F..

LAZARUS, R. (2000). Estrés y Emoción: Manejo e implicaciones en nuestra salud. Descleé de Brouwer. Madrid, España.

LAZARUS, R. y FOLKMAN, S. (1986). Estrés y procesos cognitivos. Martínez Roca. Barcelona, España.

LÓPEZ, B.; OSCA, A.; PEIRÓ, J. (2007). "El papel modulador de la implicación con el trabajo en relación entre el estrés y la satisfacción laboral" en Psicothema, 19 (1), 8187.

MAGNUNSSON, D. (1969). Teoría de los test. Trillas. México.

PELECHANO, V.; MATUD, P. y DE MIGUEL, A. (1994). Estrés, personalidad y salud. Alfaplus. Valencia.

PONCE, C. BULNES, M. ALIAGA, J. ATALAYA, M. y HUERTAS, R. (2005). "El síndrome del "quemado" por estrés laboral asistencial en grupos de docentes universitarios" en Revista de Investigación en Psicología, 8 (2), 87-112.

RAmíreZ, T.; D' AUBeTERRE, M., y ÁlVAREZ, J. (2008). “Un estudio sobre el estrés laboral en una muestra de docentes de educación básica del área metropolitana de Caracas" en Revista Extramuros, 29 (2) 69-98. 
REVISTA DE LA SEECI.

Ramírez Cuicas, Tulio; D'Aubeterre López, María Eugenia; Álvarez Rodríguez, Juan Carlos (2009): Construcción y validación de un inventario de percepción de estresores en docentes de educación básica. No 19. Julio. Año XIII. Páginas: 23- 5J ISSN: 1576-3420 DOI: http://dx.doi.org/10.15198/seeci.2009.19.23-57

RIERA, N. (2006). Efecto moderador de la inteligencia emocional en la relación entre conflicto de roles laboral - familiar y bienestar individual. Tesis de grado no publicada. Universidad Central de Venezuela. Caracas.

RUIZ BOLÍVAR, C. (2002). Instrumentos de investigación educativa. Procedimientos para su diseño y validación. CIDEG. Caracas.

TAYLOR, S. (2003). Psicología de la salud. McGraw-Hill Interamericana. México.

THORNDIKE, R.; y HAGEN, E. (1980). Test y técnicas de medición en psicología y educación. Trillas. México.

YELA, M. (1997). La técnica del análisis factorial. Biblioteca Nueva. Madrid. 